\title{
Multiculturalism and Social Values in Australia Fiction: Allan Baillie's Secrets of Walden Rising and Melina Marchetta's Looking for Alibrandi
}

\author{
María José Fernández
}

$\mathrm{B}$ $y$ the close of the twentieth century, Australian children's literature had developed themes and narrative strategies responsive to the transformation in the ethnic mix of Australian society during the second half of the century. The social and cultural developments contingent upon that transformation had inevitable effects upon the literature, entailing a different range of contents and a concomitant need to articulate values of a kind no longer grounded in a putative Anglo monoculture. The following discussion explores the values that inform contemporary Australian children's literature in response to changes in the ethnic mix. Two young adult novels, Scottish-Australian writer Allan Baillie's Secrets of Walden Rising and ItalianAustralian Melina Marchetta's Looking for Alibrandi will be discussed as representative examples of contemporary Australian children's literature. This paper will briefly explore the nature of the values of the ethnic mix in contemporary Australia, will go on to consider the benefits and incentives for children's literature in engaging with Australia's transforming ethnic mix, as well as the potential losses and disincentives, and will conclude with some suggestions about the future directions for contemporary Australian children's literature which seem presaged by the sample texts, and what this offers for Australia as a nation.

The common values informing both Alibrandi and Walden Rising which make them prime examples of contemporary Australian children's literature are a questioning of the given versions of history and a sense of antiauthoritarianism. These features allow the main characters to capture a sense of individuals making their own way within a society, mediating the conflicts between two or more distinct cultures as well as the hybrid cultures that have arisen from generations of migration. In Alibrandi. the perceived ability to write one's own life script in a way that was not possible for people of earlier generations is the most striking example of the changes in social values that have occurred in the last half of the twentieth century. This aspect is brought into sharp relief when, in a moment of stark revelation, Josie's grandmother confides in Josie about her life as a young Italian bride, her extramarital affair with an Australian man, Marcus Sandford, and the stifling social pressures which precluded the possibility of finding a new life with Sandford:

\begin{abstract}
Could you imagine how life would be for me if I married Marcus? Could you imagine what life would be for my sister? People are cruel. They would make our lives hell. But mostly, Jozzie, tink of Christina. Back then, tink of the way my darling Christina would be treated. It is not like these times, Jozzie. She would have had no one. No Australians, no ltalians. People would spit at her and say she was nuting. (p.225)
\end{abstract}

This appeal by Nonna Katia for Josie to understand the restricted life choices available to her as a young woman serves to highlight the move in society towards a culture in which the individual is given more room within the cultural canvas for personal expression and diversity. Although this shift has not occurred without resistance from the élitist and conservative establishment within society's power structures, as typified in the novel by Poison Ivy and her minor celebrity father, Alibrandi nevertheless affirms the values of non-conformism, antielitism and individualism. The result is the expression of quite irreverent, if somewhat middle class and conservative, European attitudes towards all things institutional including religion, society and culture. This carefree attitude that Josie develops through the trajectory of the narrative is born out of the experience of living in a stable and democratic country with relatively progressive social values and the realisation that her mother and grandmother have already started her out on this journey even before she was born:

Nonna Katia ... hadn't lived life the way I'd thought. She hadn't stuck to the rules and regulations. Hadn't worried about what other people thought every second of her life. She had taken chances. Broken rules. If she hadn't Mama wouldn't have been born and I wouldn't have been born. (p.226)

However, Josie does encounter racism. It is present and problematic, but it does not pose an insurmountable challenge for her as evidenced by her ability to ultimately come to grips with the contradictions of her cultural 
identity. It is through this process that she is able to reach a wider sociopolitical understanding of how she fits into contemporary Australian culture and is thus able to exercise agency regarding her social positioning, even if it is only in her own eyes:

\section{And the different cultures thing?}

Well, I'm not sure whether everyone in this country will ever understand multiculturalism and that saddens me, because it's as much part of Australian life as football and meat-pies. But the important thing is that I know where my place in life is. It's not where the Seras or the Carlys of the world have slotted me. (p.258)

Baillie's Walden Rising shares this same sense of antiauthoritarianism and a refusal to accept the given versions of history, but at a more macro level than in Alibrandi. Where Alibrand explores how family histories impact on the individual, Walden Rising explores how family histories impact on the community. Both books carry on the tradition of the bildungsroman whereby the personal is political, in the sense that the main characters' embracing of plurality, their questioning of social structures, values and prejudices, and their experiencing of alienation and isolation all have transcendental significance in terms of the Australian multicultural experience. Baillie's portrayal of Australian culture differs from Marchetta's in its depiction of that prized Australian, masculine sense of 'mateship'. In Walden Rising it is represented as a very strong uniting value within the community and between individuals. So, for example, Brendan makes the transition from 'alien' to 'mate' when he saves Bago's neck in the ruins of Walden. Brendan is initiated as a 'mate' through this acceptance by Bago who represents all things ocker in that salt-of-the-earth-battler sense of the word. Bago is depicted as the stereotypical Aussie character against whom the main protagonist, Brendan, is contrasted. Interestingly this same relationship of contrast is also set up in Alibrandi between Lee and Josie:

Lee and I have a weird relationship. We pretend we have nothing in common, yet we can talk for hours on any subject. We pretend we come from two different parts of society, yet both of us are middle-class scholarship students. We pretend that our families have nothing in common because people in her family use words like wogs and mine happen to be wogs... One day we'll pass each other in the street, pretending our lives have gone in different directions, but I can guarantee that our adult lives will be as identical as our school lives have been. (p.20)

A common message running through both books is that at the end of the day these contrasting characters are not so different from each other; that friendship and understanding are possible, and that their sense of alienation and separation are caused by a perceived sense of difference which is only a surface reality and belies the true commonality of the characters who are analogous with the cultures each represents. That is, the books expound the essentialist humanist perspective that individuals will ultimately be united by their shared humanity which will inevitably overcome any differences in culture, religion or race.

The changes in the ethnic mix of Australian society in the second half of the twentieth century have been nothing short of all-encompassing,' leaving no part of the Australian culture untouched. Marchetta overtly thematises this cultural phenomenon through her principle character, Josie, who articulates these changes and their personal as well as cultural impact towards the end of the novel:
A different Australia emerged in the 1950s. A multicultural one, and thirty years on we're still trying to fit in as ethnics and we're still trying to fit the ethnics in as Australians.
I think my family has come a long way. The sad thing is that so many haven't. So many have stayed in their own little world. Some because they don't want to leave it. others because the world around them won't let them in. (p.202)

After the recent setback for the republican cause, the festering presence of the One Nation party and the openarmed reception of the Queen during her last visit to Australia, it is safe to say that there is a real cultural nostalgia for an Anglo, monocultural Australia still present within our society. It does, however, exist alongside a relatively progressive mainstream which actively supports 
multiculturalism and sees it as a positive and defining characteristic of contemporary Australian culture. This presence, however, must not be allowed to elide the very real and day-to-day conflicts and failures in dialogue which do occur between the diverse ethnicities that coexist, contrast and blur into one another within the contemporary Australian milieu. In the same way that an individual's sense of personal identity is subject to constant change and flux, so too is a country's sense of national identity. That is, both are always necessarily involved in an ongoing process of incorporating new aspects into their sense of identity even as they are rejecting, challenging and subverting other aspects. The face of personal and/or national identity is subject to this constant shifting and changing of the tiles or units which represent the interrelated aspects of identity. However, although multiculturalism has been recognised as one of the defining characteristics of the Australian identity, it must be acknowledged that, at least in origin, multiculturalism is arguably

an artificial creation taking the form of a broad
government-supported and financed interest
group or coalition of ethnic communities, the
financing making it much easier to control. Thus
far at least, it has not been a movement which is,
to any substantial extent, self-generated and
spontaneous, or which has strong roots in the
community in a collective sense. (Hawkins 1989 ,
p.215)

That is to say that multiculturalism as a movement is a top-down phenomenon which has been accepted by the majority which recognises its aspirations to achieve a greater degree of equality and social justice for all members of society. I will return to this point below, with reference to the short and long-term function of the Australian Multicultural Children's Literature Awards and the writings of non-English speaking migrants in comparison with Aboriginal writers.

In Walden Rising, Baillie strategically brings back the English migrant to the inhospitable heart of the Australian landscape to highlight the distinctive character that Australian culture has developed since Federation. However, as an English-speaking European migrant, Brendan's brand of otherness is never so far removed from the systems of subjection and interpellation as are those of his Aboriginal and Asian counterparts, who, despite having roots going back to the town's inception or even beyond, are still regarded by the town's people as foreign at best and completely invisible at worst. So, for example, the Lee family's gradual acceptance into the community seems to have been earned through a process of self-conscious assimilation rather than a two-way cultural exchange:

Bit dull, hey? And when Tony Lee opened his mouth, forget about the Chinese look. He sounded like Bago's brother, as if he had been working long and hard on the way he sounded. (p.2)

This passage suggests that there is something 'try-hard' and not quite genuine about 'Tony's particular version of Australianness, as if it does not sit right on his Asian body. Baillie is commenting on cultural perceptions about what is 'true blue' and what is mere imitation. In contrast, there is no questioning Bago's Australianness despite the fact that his ancestors were also migrants and may not go back any further than Tony's. The language in the text, especially the use of metaphor, emphasises the naturalness of Bago's physical affinity with the Australian landscape:

Bago was freckles, hair like mouldy wheat, a block of muscle and a voice that made a galah sound sweet. (p.3)

These physical attributes are not features that Bago has as an agent and which he exists prior to and separate from, but rather they constitute him: he is this set of physical attributes. This has the effect of creating him as an exteriority. That is, he is what he does in that epic tradition of masculinity as action and which forms its contrast with the perceived passivity and interiority of femininity. This is another way that the Brendan and Bago characters are contrasted since Brendan's skill and dedication to drawing with its associated interior world of fantasies and fears position him at the feminine end of the social spectrum. The differences in their personal histories and social positioning is highlighted in the incident where one of Brendan's drawings of dead sheep incites an emotional and violent outburst in Bago which is unsurprisingly directed at Brendan. This scene serves 
to demonstrate the contrasting subjectivities of these two characters whose reactions to the one physical reality mean so completely differently that they are both at odds to understand the other's motives. Brendan misunderstands the significance of the dead sheep, just as, on a larger scale, he is slow to grasp the significance of the re-emergence of Walden, because he observes from the perspective of another culture.

Both novels are centrally concerned with the representation of other perspectives as embodied in the values of the ethnic minorities. In Alibrandi, a contrast is made between older and contemporary Australian values as well as between migrant Australians (that is, Wogs) and nonmigrant Australians (that is, Aussies). The narrative of Alibrandi marks the transition from conservative European values of family and community to a more modern, individualist perspective where self-affirmation within the frame of one's social relations is the most important factor in the definition of self:

\section{I've figured out that it doesn't matter whether I'm Josephine Andretti who was never an Alibrandi, who should have been a Sandford and who may never be a Coote. It matters who I feel like I am - and l feel like Michael and Christina's daughter and Katia's grand-daughter; Sera, Anna and Lee's friend and Robert's cousin. (p.261)}

In Walden Rising, the social values of contemporary Australia are represented within the context of a "boys own' coming of age narrative which notably steers away from the type of sexual or gender politics evident in Alibrandi. Baillie's novel concems itself more with class and racial politics, as well as the politics of history which determine whose version of events get told and built into the foundations of a community and culture. Walden Rising explores the reasons why some versions of history are told and retold until they become lore/law, whilst others are driven underground and kept alive only by the voices of dissent. The version of history which the dominant power structure perpetuates in Walden Rising is one which has literally drowned out the Asian story as well as the Aboriginal story. That is, in the same way in which water has physically drowned out the secondary evidence of the dissenting versions of Walden's history, so too has the town's establishment tried to drown out the remaining residues of primary evidence. Notably, it is the drought that brings about a crumbling away of the social and cultural edifices, and allows the younger generation to explore these other stories, or rather, these stories of the Other which threaten to undermine those of the establishment:

\section{i) He looked at the tilted wheel that marked the diggings, where men were attacked with pick- handles and torches. The stories of Harry and Tony had changed Walden into a town of murder. That made all the difference. (p.72)}

ii) My family was here before Walden, almost as early as Bago.

Nobody told me. Everyone forgets. But not Grandad. Before he died Grandad told me everything. My ancestor Lee Weyun came to the diggings only a few months after the Bagos. (p.52)

As remarked earlier, the social value of 'mateship' runs right through Baillie's novel and the story marks the main character's induction into that fraternity. As a result, a more linear and unitary concept of social values is created in Walden Rising than in Alibrandi despite the fact that Baillie uses third person narration which potentially provides more diversity in terms of reader positioning. On the other hand, it is arguable that the use of first person narration in Alibrandi, in conjunction with its unabashed embrace of the politics of advocacy, work against its own aims by verging on didacticism, and the novel is only saved from this fate as a result of the freshness and unconventionality of its voice. The narrative in Walden Rising, like that of Alibrandi, marks a breakdown in the existing structures of a society and represents individuals as well as whole communities in a state of transition. This is a common feature in narratives which thematise multiculturalism. That is, changes in the individual are represented as being metonymically linked to the changes occurring in the society as a whole. For example, Chapter Thirteen opens with what seems to be Brendan's observation of a change in the landscape of Walden, but in reality it represents a change in the perception of the nature of the landscape. Brendan's reaction is represented 
as metonymic of the changes occurring in the minds of all the townspeople and, as a result, to the town itself:

\section{On Sunday Brendan rode back into the hills. He stood on the levelling bank and stared at Walden \\ You're changing, he said. \\ Everyone was changing now. \\ Brendan shook the idea away and concentrated on the town. The town was bigger now. (p.71)}

That both texts are concerned with themes of change and transition prompts the larger question of how successfully contemporary Australian children's literature has been able to reflect cultural change. It is undeniable that by speaking in a more contemporary voice which is in tune with the realities facing Australia's youth today these texts are able to reach a wider local audience. By thematising the experiences of the migrant other they serve not only to validate it within the wider community, but also to validate the experiences of non-migrants whose lives are shaped by the all-encompassing effects of multiculturalism. A formal and institutional attempt to promote a more inclusive and plural literature was embodied in the short-lived AMCL Awards, established in 1991. The Award's objectives, while not subtle, envisaged a quality literature that articulated the ideals of multiculturalism:

i) all Australian children should see themselves reflected in the stories they read, whether they come from Australian, Estonian, Chinese, Greek or Anglo Australian backgrounds, and

ii) because values about cultural and social diversity are formed very early in life, it is important that children's literature reflect the multicultural issues of the day, so that children will grow up better placed to understand and appreciate our society.

(Austin 1993, p.203)

These principles have, of course, permeated the literature beyond such institutional idealism, and a significant strand of Australian children's literature continues to function as a medium highly relevant to the (multi)culture of contemporary society: the literature engages in a dynamic and innovative dialogue with the discourses that produce it and then functions in a socially progressive manner. Austin (1993) asserts that what we should in fact aim for is a literature in which 'multicultural society is just a fact of life - no comment is needed (this to my mind is virtually post-multicultural)' (p. 204). However, it is arguable that such a literature can only be a product of a society which has fully come to grips with its cultural plurality on all fronts and which is no longer threatened by the pervasive and ongoing inclusion of the Other into the mainstream. As both Alibrandi and Walden Rising suggest, Australia has still some way to go before this type of post-multicultural literature can become a true reflection of contemporary Australian society as well as an easily identifiable literary genre of its own.

There are various ways in which both Alibrandi and Walden Rising can be seen as examples of a literature which pushes the boundaries of traditional literary conventions that ultimately function to reinforce and reproduce the existing cultural norms within a society. One of the most obvious examples of unconventionality is the manner in which Marchetta has chosen to depict her sole focaliser, Josie, as a very articulate and politically aware young woman whose opinions and observations strongly advocate freedom of choice and expression in a number of lengthy diatribes, monologues and speeches that litter the text to the extent that they read like authorial opinions only lightly filtered through a fictional character. For example:

I'm an Italian. I'm of European descent. When an Italian or another person of European descent calls me a wog it's done in good warm humour. When the word 'wog' comes out of the mouth of an Australian it's not done in good humour unless they're a good friend. It makes me feel pathetic and it makes me remember that I live in a small-minded world and that makes me so furious. (p.88)

These moments of clarity and introspection are, on the one hand, the stuff of bildungsroman because they allow for the exploration of subjectivity and the growth and development of the individual. On the other hand, they are also what causes the narrative to run the risk of 
restricting the reader's ability to move freely amongst the discourses of the text because of their strong advocacy standpoint and limited reader positioning. This is compounded by Marchetta's use of a single first person narrator which provides only one focalising perspective. What saves the text from potentially being labelled didactic and ultimately makes it an example of an unconventional text is the voice with which this single focaliser speaks. That is, the voice of the Wog other, not the migrant variety, but the second generation variety, who despite having parents who were born here, still maintain a strongly perceived sense of difference from those identified within the mainstream culture as unquestionably Aussie. This particular construction of subjectivity around notions of inherited and inherent difference from the cultural norms or traditions is one that is shared by a sizeable part of the Australian population. It is arguable that each identifiable group in Australia has its own definition about what it is to be Australian depending on their experiences of living in this country, and because Australia is such a diverse society the spectrum of experience varies greatly and so too do the definitions. Despite this reality, in 1992 when Alibrandi was published it was easily identifiable as unconventional in mainstream children's literature because of its construction of a definition of what it was to be Australian from the perspective of the Wog Other. In spite of an official policy of cultural inclusion, it is undeniable that not until quite recently have fundamentally different and at times incompatible definitions of what it is to be Australian been truly valorised. That is, the mainstream media and other cultural mediums have only very recently begun to adopt a more pluralist approach to the types of Australianness that they celebrate and propagate. These differing definitions do not exist in isolation to one another, but rather contest, complement and confuse one another. So, although they represent discrete units, each different definition represents an integral part of the whole picture, which in this case is that of the Australian national identity.

These questions of identity are explored at the level of the individual in both Walden Rising and Alibrandi as young people interrogate their grandparents' generation so as to disclose and challenge hidden truths which will help resolve the tensions and conflicts which are impeding their personal growth. While this is undeniably a convention of the coming of age narrative, in Walden Rising it is used to unconventional ends. For example, when Old Man Harry begins suddenly to remember things about Walden's history and Tony recalls his grandfather's version of events, the dissenting history of the victims of the cultural war that was waged during the town's formation is finally voiced:

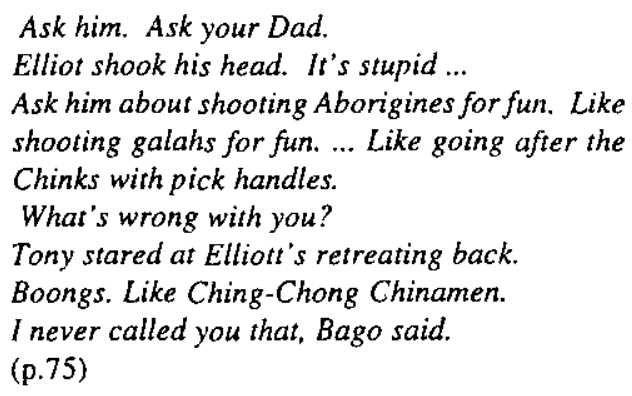

What this exchange serves to uncover is more than simply the crimes and injustices of the past. It also highlights the way that racism is a refusal to acknowledge given facts. In this instance, it is Elliot's refusal to acknowledge the violent racism that his forefathers perpetrated against the Chinese members of the community as well as the local Aboriginal people. There is also on the part of Elliot's father and grandfather the refusal to acknowledge the common humanity of the Chinese and Aboriginal people. The reason that the names Chinks or Boongs offend Tony so profoundly is that they are a form of verbal violence and represent a powerful mechanism whereby one group can efface the sense of shared humanity with another group to such a degree that they can be relentlessly persecuted and even killed in cold blood without guilt or punishment. Tony likens the injustices committed against the Aboriginal people with those committed against the Chinese people. This empathy for the injustices suffered by the Aboriginal people is, according to Goodwin (1986), born out of a sense of co-habitation within the margins of Anglo-Celtic Australian culture. That is, Tony recognises that the violence against both peoples was incited by the same xenophobia, and sense of fear and loathing for the 
Other by the Anglo monoculture that dominated the town of Walden. This is a voice not of ten heard in contemporary Australian children's literature and challenges all manner of stereotypes and prejudices regarding the segregation of cultural communities within the wider society. Goodwin (1986) writes,

While all white Australian writers are migrants or the descendants of migrants, those who come from non-English speaking countries commonly express feelings of alienation, loss and rejection akin to those of Aboriginal writers. (p.267)

Effectively, this element of shared (albeit negative) experience between groups which are culturally very different allows the multicultural movement to go beyond being merely an artificially implemented social policy to one which informs and shapes the way in which individuals make meaning of their own cultural positioning and that of others. This point serves to highlight the very real need in multicultural Australia for a contemporary literature which engages in an ongoing dialogue with the changing face of its society. Sustained critical commentary addressing social values is a requirement of any democratic society. Xie (1999) advocates the implementation of the politics of difference within the post-colonial context as the key to achieving a greater degree of social equality and political power. He goes on to aver that

For all kinds of people who are socially, politically, and ethnically marginalized to claim legitimacy and sovereignty, they have to assert themselves as unassimilable and unsubsumable. They owe their discursive power to critiquing, interrogating, and unsettling the repressive imperial total system of social life. (p.9)

It is for these reasons that we need to hear all voices, dissenting and otherwise, because silence can only breed complacency, ignorance and the type of political apathy which has arguably plagued the Australian cultural climate in the past few decades, and makes it ripe for the growth of intolerance and vilification within the more disenchanted sectors of the community who do not see themselves as benefiting from the radical change in our ethnic make-up, nor from the gradual move towards the realisation of the ideals of Aboriginal reconciliation.
Both Alibrandi and Walden Rising were written in the last decade of the twentieth century, a decade characterised by a political and social climate of sweeping change and ongoing questioning about what it was to be Australian. Since personal developments traced in the bildungsroman are analogous with wider changes in society, this genre is particularly pertinent to Australia and its hesitant growth towards independence from the 'mother country', a process which has thus far involved attempts to find a place for itself on the map in relation to its Asian neighbours and colonial cousins, while at the same time reconciling with its indigenous peoples, past and present.

In conclusion, Alibrandi and Walden Rising may be seen as exemplifying the type of contemporary Australian children's literature which is heading towards a greater understanding of the debates that resonate and rumble within the Australian community at both the personal and national levels. It is important that our young adult fiction deal with these issues and tensions in society because that is how a literature stays relevant and integral to a culture. It is also the way in which we can hear the voices on all sides of the debates, voices which may well be those of the reading audience, who may hitherto have been unable to articulate their own particular sense of being within our culture, as it is only recently that the voices of such ethnic minorities have seemingly been of sufficient value to warrant a sizeable literature and literary debate of their own. The success and proliferation of this writing can be seen as fostering a greater sense of national identity by producing a distinctly Australian children's literature which has the capacity to speak in the voices of those who are marginalised by its mainstream culture. In this manner, both Alibrandi and Walden Rising may be seen as functioning as mechanisms of incorporation; as texts which help to open the channels of cross-cultural exchange and social debate, and which in turn serve to minimise the marginalising potential of being an ethnic minority. This is because a group, however small, will be protected from the extremes of alienation from the heartcentre of a society so long as that group has a voice and vote. Therefore, since Australia's longstanding democratic system of government ensures the latter, what we must now strive for is to ensure the former by 
fostering the production of Australian texts which give voice to the smaller pieces of the entire cultural mosaic which make up the whole picture of contemporary Australia society today.

\section{$\rightarrow$ D.EK}

\section{NOTES}

1. Hugo remarks that the twentieth century saw a transformation of Australia from an overwhelmingly Anglo-Celtic, homogenous population in which $95,2 \%$ had been bom in Australia, the United Kingdom or Ireland, to one of the world's most multicultural societies by 1996 when $16.2 \%$ had been born elsewhere. Moreover, 19\% were Australian-born persons with at least one parent born overseas and $8 \%$ had at least one parent born in a country in which English is not the main language' (Hugo 2001, p. 12).

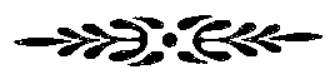

\section{REFERENCES}

Austin, Meredith. (1993) 'The Australian Multicultural Children's Literature Awards' in Australian Children's Literature: Finding a Voice, Michael Stone (ed). Wollongong, New Literatures Research Centre, pp. 203206.

Baillie, Allan. (1996) Secrets of Walden Rising. Ringwood, Viking.

Goodwin, Ken. (1986) Macmillan History of Literature: A History of Australian Literature. London, Macmillan Publishing.

Hawkins, Freda. (1989) Critical Years in Immigration: Canada and Australia Compared. Sydney, New South Wales University Press.
Hugo, Graeme. (200I) 'Population. Centenary article: A century of population change in Australia' (Year Book Australia, 2001). Australian Bureau of Statistics. www.abs.gov.au

Marchetta, Melina. (1992) Looking for Alibrandi. Ringwood, Penguin.

Xie, Shaobo. (1999) 'Rethinking the identity of cultural Otherness: The discourse of difference as an unfinished project', in Roderick McGillis (ed) Voices of the Other. New York, Garland, pp. 1-16.

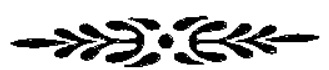

\section{BIOGRAPHICAL NOTE}

María José Fernández was born in Costa Rica and grew up in Sydney. She completed her Master of Arts in Children's Literature at Macquarie University in June 2001 and now works in publishing currently at the Australian Consolidated Press. Her plans are to travel in 2002 and undertake $\mathrm{PhD}$ program when she returns. As a research topic of choice for further study she is interested in exploring the cultural developments in contemporary Australian children's poetry. In 2000 she won the ACLAR (Australasian Children's Literature Association for Research) Award for the essay above. This award is presented every two years for the best essay on children's literature submitted by a postgraduate student. 